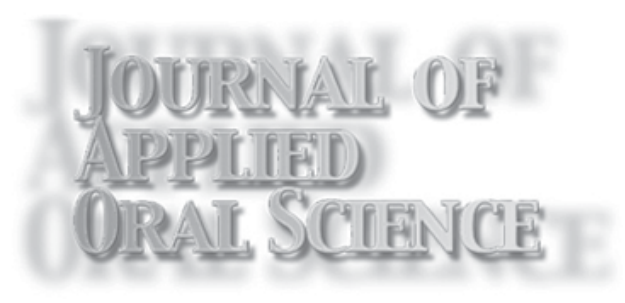

ISSN 1678-7757

\title{
Editorial
}

\section{The Journal of Applied Oral Science is selected for coverage in the Science Citation Index Expanded ${ }^{\mathrm{TM}}$}

Dear Readers and Reviewers,

At first sight this editorial may seem repetitive for some of you. Actually, it is! But the difference from the other editorials in which we acknowledged all of you is that in the previous ones we did not have such a remarkable achievement to share with you. At this moment I am very proud to announce that the Journal of Applied Oral Science (JAOS) has been recently selected for coverage in the Science Citation Index Expanded $^{\mathrm{TM}}$ (SCIE). Indexing of this title will start with 2008 issues.

The SCIE provides access to current and retrospective bibliographic information, author abstracts, and cited references found in approximately 5,900 of the world's leading scholarly science and technical journals covering more than 150 disciplines. The SCIE format is available through Web of Science ${ }^{\circledR}$ and the online version, SciSearch ${ }^{\circledR}$. It allows researchers to conduct broad-based, comprehensive searches that uncover all the relevant information they need; provides cited reference searching, the unique ISI search and retrieval feature that lets users track the literature forward, backward, and through the database, breaking through disciplinary and geographic boundaries, as well as enables users to conduct multidisciplinary searches to discover hidden subject relationships.
We truly believe such an important accomplishment was only possible due to the hard and committed work of our reviewers. We hope to keep on counting on your precious help because it will be instrumental in order to have the JAOS indexed in other important bibliographic citation databases. We greatly value your advice and appreciate the time and effort involved in preparing a report. Obviously, once more, we need to thank the authors, who believed in our serious work, and chose the JAOS to publish their articles.

I take advantage of this message to invite you to visit our free complete online collection at http:// www.scielo.br/scielo.php.

Please, also send your suggestions and comments to improve the quality of our online submission system (http://submission.scielo.br/index.php/jaos/login).

Warm regards,

\author{
Carlos F. Santos, DDS, PhD, \\ Associate Professor \\ Editor-in-Chief \\ Journal of Applied Oral Science
}

